\title{
Condições teóricas para a integração epistemológica da Arquivologia, Biblioteconomia e Museologia na Ciência da Informação
}

\author{
Theoretical conditions for epistemological integration of Archival Science, Library Science \\ and Museum Studies in Information Science
}

Carlos Alberto Avila Araújo

Doutor em Ciência da Informação. Pós-doutorando pela Universidade do Porto Professor adjunto da Escola de Ciência da Informação/UFMG.

E-mail: casalavila@yahoo.com.br

\begin{abstract}
Resumo
Neste artigo são apresentadas as condições teóricas que possibilitam a integração epistemológica da Arquivologia, da Biblioteconomia e da Museologia no escopo da Ciência da Informação. Para isso, são apresentadas primeiramente as conformações históricas que propiciaram essas três áreas e o estabelecimento de um primeiro modelo de cientificidade. A seguir, são apresentadas diversas teorias formuladas ao longo do século $\mathrm{XX}$, agrupadas em cinco eixos, que apontam para superações do modelo inicial. Por fim, esse quadro é confrontado com os desenvolvimentos teóricos da Ciência da Informação. Argumenta-se que o conceito de informação tal como estudado recentemente pode favorecer o avanço das perspectivas teóricas nas três áreas e aponta para a possibilidade de sua integração epistemológica.
\end{abstract}

Palavras-chave: Ciência da Informação; Arquivologia; Biblioteconomia; Museologia.

\begin{abstract}
In this article are presented the theoretical conditions for epistemological integration of Archival Science, Library Science and Museum Studies in the scope of Information Science. For that, first, are presented the historical conformations that led these three areas, until the establishment of a first scientific model. Following, are presented several theories formulated during the twentieth century grouped into five axes, which point to overrun the initial model. Finally, this framework is confronted with the theoretical developments in Information Science. It is argued that the concept of information as recently studied may foster the advancement of theoretical perspectives in the three areas and points to the possibility of its epistemological integration.
\end{abstract}

Keywords: Information Science; Archival Science; Library Science; Museum Studies.

\section{Introdução}

Recentemente, a Escola de Ciência da Informação da Universidade Federal de Minas Gerais criou os cursos de graduação em Arquivologia e Museologia, que passaram a constituir, junto com o já existente de Biblioteconomia, três campos integrados na Ciência da Informação (CI). Uma vez garantidas as condições institucionais da composição destes cursos, restou a tarefa de consolidar as condições teóricas - o que é, na verdade, um processo

InCID: R. Ci. Inf. e Doc., Ribeirão Preto, v. 2, n. 2, p. 19-41, jul./dez. 2011. 
permanente de construção científica, uma tarefa a ser executada no dia-a-dia do ensino e da pesquisa. Este texto tem por objetivo apresentar argumentos em defesa da ideia de que é possível e desejável promover a integração epistemológica entre as áreas da Arquivologia, Biblioteconomia e Museologia, no campo da CI, dadas certas condições teóricas, que serão aqui analisadas. Pretende-se demonstrar que a evolução teórica das três áreas (e alguns desdobramentos práticos), ao longo do século $\mathrm{XX}$, tem apontado frequentemente para a superação das distinções disciplinares entre elas - e, portanto, para a sua integração. Nesse cenário, a CI e o conceito de informação surgem como possíveis aglutinadores e potencializadores dos desenvolvimentos futuros destas três áreas.

Para cumprir o objetivo proposto, neste texto recorre-se a alguns elementos históricos da evolução destas áreas, mas sem a pretensão de uma leitura historiográfica. O interesse se localiza no plano epistemológico, da produção dos conhecimentos - daí a análise recair exatamente sobre a produção teórica nas três áreas. A seguir, após um breve panorama da CI, confronta-se os dois quadros para a defesa da integração epistemológica.

\section{Das origens à consolidação disciplinar e paradigmática}

Refletir sobre os campos de conhecimento da Arquivologia, Biblioteconomia e Museologia conduz às primeiras atividades culturais humanas - entendendo aqui cultura como a ação simbólica, humana, de interpretar o mundo e de produzir registros materiais dessas ações em qualquer tipo de suporte físico. Mas é com a invenção da escrita e do estabelecimento das primeiras cidades, no início dos processos de sedentarização das coletividades, há mais de cinco milênios, que aparecem as primeiras manifestações de espaços específicos voltados para a guarda e a preservação de acervos documentais. Autores que tratam da história dos arquivos, bibliotecas e museus frequentemente listam algumas instituições que se tornaram paradigmáticas (como os arquivos de Ebla, a Biblioteca de Alexandria, o Mouseion alexandrino), embora distinções muito rígidas do que seria arquivo, biblioteca ou museu se revelem infrutíferas (SILVA, 2006). No Egito Antigo, na Grécia Clássica, no Império Romano, nos mundos árabe e chinês do primeiro milênio e na Idade Média na Europa, ergueram-se e consolidaram-se numerosos arquivos, bibliotecas e museus, relacionados com os mais diversos fins - religiosos, políticos, econômicos, artísticos, jurídicos, entre outros.

InCID: R. Ci. Inf. e Doc., Ribeirão Preto, v. 2, n. 2, p. 19-41, jul./dez. 2011. 
Contudo, é com o Renascimento, a partir do século XV, que aparecem os primeiros traços efetivos daquilo que se poderia chamar de um conhecimento teórico específico nas três áreas, com a publicação dos primeiros tratados relativos a estas instituições. Nesta época, renasce o interesse pela produção humana, pelas obras artísticas, filosóficas e científicas tanto as da Antiguidade Greco-Romana como aquelas que se desenvolviam no próprio momento. Salientou-se assim o interesse pelo culto das obras, pela sua guarda, sua preservação.

Proliferaram, entre os séculos XV e XVII, tratados e manuais voltados para as regras de procedimentos nas instituições responsáveis pela guarda das obras, para as regras de preservação e conservação física dos materiais, para as estratégias de descrição formal das peças e documentos, incluindo aspectos sobre sua legitimidade, procedência e características. A produção simbólica humana, compreendida como um "tesouro" que precisaria ser devidamente preservado, torna-se objeto de uma visão patrimonialista (o conjunto da produção intelectual e estética humana, a ser guardado e repassado para as gerações futuras). Contudo, o foco do interesse fixa-se no conteúdo dos acervos, constituindo arquivos, bibliotecas e museus apenas em instituições a serviço dos campos de estudo da Literatura, das Artes, da História e das ciências. Não se constroem, neste momento, conhecimentos arquivísticos, biblioteconômicos ou museológicos consistentes (para além de algumas regras operativas muito próximas do senso comum), mas apenas conhecimentos artísticos, literários, filosóficos ou históricos sobre os conteúdos guardados nestas instituições.

O passo seguinte na evolução destas áreas do conhecimento se dá com a Revolução Francesa e as demais revoluções burguesas na Europa, que marcam a transição do Antigo Regime para a Modernidade. Opera-se uma profunda transformação em todas as dimensões da vida humana (na política, na economia, no direito) e, dessa forma, também os arquivos, as bibliotecas e os museus são drasticamente transformados. Surgem os conceitos modernos de “Arquivo Nacional”, "Biblioteca Nacional”, "Museu Nacional”, que têm no caráter público (no sentido de "nacional", relativo ao coletivo dos nascentes Estados modernos) sua marca distintiva. São formadas as grandes coleções, operam-se amplos processos de aquisição e acumulação de acervos - o que reforçou a natureza custodial destas instituições. A necessidade de se ter pessoal qualificado para as nascentes instituições modernas levou à formação dos primeiros cursos profissionalizantes, voltados essencialmente para regras de administração das rotinas destas instituições e, seguindo a tradição anterior, para conhecimentos gerais em Humanidades (ou seja, os assuntos dos acervos guardados).

InCID: R. Ci. Inf. e Doc., Ribeirão Preto, v. 2, n. 2, p. 19-41, jul./dez. 2011. 
Por fim, com a consolidação da ciência moderna como forma legítima de produção de conhecimento e de intervenção na natureza e na sociedade, também o campo das humanidades se vê convocado a constituir-se como ciência. Surgem então, ao longo de todo o século XIX, diversos manuais que buscam estabelecer o projeto de constituição científica da Arquivologia, da Biblioteconomia e da Museologia. O modelo de ciência então dominante, oriundo das ciências exatas e naturais, voltado para a busca de regularidades, estabelecimento de leis, ideal matemático e intervenção na natureza por meio de processos técnicos e tecnológicos, se expande para as ciências sociais e humanas através do Positivismo. Esse é o modelo que inspira as pioneiras conformações científicas das três áreas, que privilegia os procedimentos técnicos de intervenção: as estratégias de inventariação, catalogação, descrição, classificação e ordenação dos acervos documentais de arquivos, bibliotecas e museus. Opera-se um verdadeiro "efeito metonímico": aquilo que antes era uma parte do processo (operações técnicas para possibilitar o uso das coleções) se torna o núcleo, o essencial, em alguns casos a quase totalidade do conteúdo dos nascentes campos disciplinares. Arquivologia, Biblioteconomia e Museologia tornaram-se as ciências (positivas) voltadas para o desenvolvimento das técnicas de tratamento dos acervos que custodiam. Ao mesmo tempo, o movimento de consolidação positivista destas áreas de conhecimento promove, de uma só vez, sua "libertação" de outras áreas das quais eram apenas campos auxiliares (como as Artes, a História, a Literatura) e a sua autonomização científica, sendo por meio desta que se opera a separação efetiva entre as três áreas, cada uma com seu conjunto específico de técnicas.

Mais do que oposições, os três movimentos acima destacados se somam. A perspectiva patrimonialista volta-se para os "tesouros" que devem ser custodiados, ressaltando a importância da produção simbólica humana. Ainda que preservado em parte o sincretismo verificado nos séculos anteriores, há já alguma distinção entre arquivos, bibliotecas e museus. A entrada na Modernidade enfatiza as especificidades das instituições arquivos, bibliotecas e museus, que devem ter estruturas organizadas e rotinas estabelecidas para o exercício da custódia. E a fundamentação positivista prioriza as técnicas particulares de cada instituição a serem utilizadas para o correto tratamento do material custodiado. Constituem-se assim, nos finais do século XIX e início do século XX, os elementos que marcam a consolidação de um paradigma patrimonialista, custodial e tecnicista (SILVA, 2006) para as três áreas.

Um dos efeitos mais sensíveis deste modelo é que, ao privilegiar a dimensão física das coleções, em seguida as instituições que as guardam e finalmente as técnicas operadas para seu tratamento, ele efetivamente promove e incentiva a separação das três áreas e sua 
constituição como campos científicos autônomos. Tal fato se complementa com as ações, cada vez mais incisivas, nas primeiras décadas do século $\mathrm{XX}$, das associações profissionais em prol do estabelecimento das distinções entre os profissionais de arquivo, de biblioteca e de museu. Profissionais diferentes, em instituições diferentes, utilizando técnicas diferentes para o tratamento de acervos específicos - tal é a resultante da soma das ações ocorridas no plano teórico (com o paradigma custodial) e prático (com o fortalecimento das instituições, dos movimentos profissionais e associativos, e o início dos primeiros cursos universitários).

Ao longo do século XX, contudo, o desenvolvimento de reflexões e teorias nas três áreas não conduziu ao fortalecimento do paradigma dominante. Ao contrário, a vasta produção científica que se seguiu identificou, com muita freqüência, os vários limites desse modelo, ressaltando diversos aspectos que, pouco a pouco, foram conduzindo à necessidade de sua superação. Além disso, novos fatores e elementos surgidos neste século (como a crescente importância da informação e do conhecimento nos setores produtivos da sociedade, o desenvolvimento das tecnologias digitais, o incremento das práticas interdisciplinares no ambiente científico e a crescente importância da especificidade das ciências sociais e humanas) também exerceram importante papel na mudança do cenário de atuação de arquivos, bibliotecas e museus, conduzindo a iniciativas práticas que também evidenciavam mudanças no paradigma dominante. Em meio a tudo isso, surgiu, em meados do século XX, a Ciência da Informação, com uma proposta de cientificidade capaz de acolher e potencializar os diferentes aspectos ressaltados pela produção teórica da Arquivologia, Biblioteconomia e Museologia - como se pretende demonstrar a seguir.

\section{As teorias e reflexões desenvolvidas no século XX}

A diversidade de conhecimentos científicos e teóricos produzidos sobre arquivos, bibliotecas e museus, tanto nos próprios campos científicos como em outras áreas (como a História, a Pedagogia, a Literatura, entre outros), torna extremamente difícil apresentar ou mapear essa produção. Para os fins deste artigo, optou-se por um arranjo que privilegia a discussão aqui empreendida. Seria possível listar e agrupar as diversas teorias e autores sob uma variedade imensa de outros aspectos (região geográfica, época histórica, disciplina de origem, inspiração filosófica, etc), mas optou-se por agrupar as variadas contribuições produzidas pelos aspectos que apontaram elementos de superação do paradigma custodial e tecnicista predominante.

InCID: R. Ci. Inf. e Doc., Ribeirão Preto, v. 2, n. 2, p. 19-41, jul./dez. 2011. 


\section{Os estudos de inspiração funcionalista}

Já no final do século XIX, ensaios, manifestos e iniciativas vinham reivindicando mudanças nos arquivos, bibliotecas e museus, por meio de expressões como "arquivo efetivamente útil", "biblioteca viva", "museu dinâmico", entre outras. Criticava-se o fato de estas instituiçõoes estarem voltadas apenas para seus acervos e suas técnicas, sugerindo que elas se "mexessem", buscassem atuar ativamente nos contextos sociais em que se inseriam. E, ao propor isso, provocaram também mudanças consideráveis nas formulações teóricas.

Em comum, essas várias manifestações têm como fundamento o Funcionalismo. Trata-se de uma perspectiva que se sustenta numa visão da realidade humana a partir da inspiração biológica do organismo vivo. A sociedade humana é entendida como um todo orgânico, composto de partes que desempenham funções específicas necessárias para a manutenção do equilíbrio do todo. Estudos funcionalistas se voltam, pois, para a determinação das funções (no caso, dos arquivos, das bibliotecas e dos museus), para verificar se as funções estão ou não sendo cumpridas (e para a identificação e eliminação dos obstáculos que impedem seu cumprimento), para a identificação de disfunções que possam estar ocorrendo e a formulação de estratégias para superá-las. Por todo o raciocínio encontrase a ideia de eficácia: a investigação científica como fator para impulsionar o funcionamento adequado das instituições e, consequentemente, o desenvolvimento e o progresso das sociedades.

No campo da Arquivologia, as primeiras manifestações deste pensamento se encontram nos manuais pioneiros de Jenkinson, de 1922, e de Casanova, de 1928, que apontavam para a necessidade de os arquivos terem um impacto efetivo no aumento da eficácia organizacional. Mas é com o desenvolvimento da subárea de Avaliação de Documentos, assumindo para o campo a tarefa de eliminação dos documentos, que um pensamento pragmatista mais efetivo começou a formular-se. Sua maior expressão se deu com a chamada "escola norte-americana" da primeira metade do século XX, com os trabalhos de Warren (a partir dos quais formalizou-se uma associação que seria o embrião da American Records Management Association); de Brooks, sobre as três categorias de valor, e principalmente de Schellenberg,, sobre o valor primário e secundário dos documentos arquivísticos (DELSALLE, 2000). Em conjunto, tais proposições visavam conservar o máximo de informação preservando um mínimo de documentos - priorizando a 
funcionalidade em oposição aos aspectos de arranjo e valor histórico dos documentos. Uma outra vertente arquivística, bastante distinta das anteriores, mas também funcionalista, é a que prioriza a ação cultural dos arquivos, suas funções culturais e pedagógicas, que também provocou a busca por uma maior "dinamização" destas instituições (ALBERCH I FUGUERAS et al, 2001).

No campo da Biblioteconomia, é preciso retornar a meados do século XVIII para encontrar as primeiras manifestações em prol das bibliotecas efetivamente públicas, na Inglaterra e, posteriormente, nos EUA (MURISON, 1988). O termo "efetivamente" ressalta que as primeiras bibliotecas modernas, embora "públicas" no nome, seriam demasiadamente auto-centradas e elitistas. Atos, manifestos e iniciativas práticas no campo das bibliotecas públicas (Public Library Movements), liderados por bibliotecários como Mann e Barnard, buscaram romper com o isolamento destas e atrair cada vez mais pessoas para seu espaço. Já em 1876, Green defendia inovações práticas nas bibliotecas para aumentar a acessibilidade física e intelectual, sendo o precursor dos posteriormente chamados serviços de referência (FONSECA, 1992). A consolidação científica dessa vertente se deu na Universidade de Chicago, onde em 1928 foi criado o primeiro doutorado em Biblioteconomia. Autores como Butler, Shera, Danton e Williamson defendiam uma Biblioteconomia científica, voltada não para os processos técnicos mas para o cumprimento de suas funções sociais - ou seja, o fundamento da biblioteca se encontra no fato de ela ir ao encontro de certas necessidades sociais. Shera chegou a propor um novo espaço de reflexão científica, a "Epistemologia Social”, para o estudo do papel do conhecimento na sociedade. Teóricos de diferentes países, tais como Lasso de la Vega, Litton, Buonocore, Mukhwejee e Usherwood, seguiram essas orientações, ao defender o conceito de biblioteca como instituição democrática, ativa, e não como depósito de livros (LÓPEZ CÓZAR, 2002). Na Índia, Ranganathan, numa clara perspectiva funcionalista, desenvolveu as cinco "leis" da Biblioteconomia, defendendo o efetivo uso da biblioteca e de seus recursos e, ao mesmo tempo, o atendimento às necessidades da sociedade, por meio do atendimento a cada um de seus componentes. Desenvolvimentos posteriores de leis ou princípios da Biblioteconomia, como os de Thompson e de Urquhart, também priorizaram as funções sociais e a necessidade da biblioteca ser dinâmica e ativa. Recentemente, estudos sobre as tipologias de bibliotecas e sobre os impactos das tecnologias audiovisuais e digitais de informação também se inserem nesta perspectiva, buscando otimizar o papel da biblioteca e dinamizar o uso de seus recursos. 
No campo da Museologia, o maior destaque é a área de Museum Education, que se desenvolveu sobretudo no ambiente anglo-saxão. Conforme Gómez Martínez (2006), trata-se de uma museologia "verbal”, voltada para a ação, erigida em oposição à tradição cujo símbolo maior é o Louvre - a tradição "nominalista", voltada para a posse e a descrição dos objetos. Zeller (1989) aponta que floresceu, principalmente nos EUA do final do século XIX e início do século XX, uma Museologia voltada para a eficácia dos museus, para uma efetiva difusão de certos valores junto à população, e para oferecer à sociedade um "retorno" dos investimentos feitos. Autores como Flower, Goode, Dana, Rea e Coleman marcavam a especificidade dos novos museus como instituições que teriam como valor não a contemplação mas o uso, e que não esperariam pelos visitantes, mas iriam "buscá-los", atraindo-os para os museus por meio da eliminação de barreiras e da busca por acessibilidade. Diversas parcerias foram realizadas com o setor privado para o incremento de atividades industriais e comerciais, resultando em inovações museográficas. Essa perspectiva manifestou-se em diversos outros contextos. Na França, destaca-se o pioneirismo do "museu imaginário" de Malraux, no plano teórico, e do Centro Pompidou, em Beaubourg, como aplicação prática. No Canadá, aproximações foram feitas entre os museus e o conceito de “comunicação" a partir dos trabalhos de Cameron. A partir da década de 1980, com as tecnologias digitais, houve uma revitalização da corrente funcionalista, com as possibilidades de acesso remoto, interatividade e design de exposições, com manifestações em várias escolas e correntes como, por exemplo, no grupo de pesquisadores ligados à Universidade de Leicester (Merriman, Pearce, Arnold, Hooper-Greenhill, entre outros) e, ainda no contexto inglês, com a "Nova Museologia" defendida por Vergo e outros. Outras subáreas mais específicas da Museologia, também funcionalistas, são a dos estudos em tipologias de museus (já que, a diferentes tipos, correspondem diferentes funções) e a de gestão de museus a partir de estratégias de marketing, envolvendo autores como Moore e Tobelem.

\section{A perspectiva crítica}

Abordagens críticas sobre os fenômenos humanos e sociais se desenvolveram intensamente desde o século XIX como reação ao pensamento positivista. Onde as recentes ciências humanas e sociais buscavam estabelecer padrões e regularidades, as manifestações críticas denunciavam o caráter histórico da realidade, reivindicando o estudo dos contextos históricos para a compreensão dos fenômenos. Em oposição ao Funcionalismo, que almejava

InCID: R. Ci. Inf. e Doc., Ribeirão Preto, v. 2, n. 2, p. 19-41, jul./dez. 2011. 
o bom funcionamento do social, as teorias críticas argumentavam que o conflito, e não a integração, constitui o principal fundamento explicativo da realidade humana. A partir de uma postura epistemológica de suspeição, desenvolveram-se abordagens críticas em praticamente todas as ciências sociais e humanas - e, também, nos campos da Arquivologia, Biblioteconomia e Museologia. Arquivos, bibliotecas e museus passaram a ser estudados não mais com o intuito de identificar as funções que deveriam desempenhar para o bom funcionamento do todo social mas, sim, a partir de seu papel nas dinâmicas de poder e dominação, principalmente a partir da denúncia de suas ações ideológicas.

No âmbito da Arquivologia, os primeiros traços de pensamento crítico encontram-se em análises de pesquisadores como Bautier, sobre os interesses ideológicos que motivaram critérios usados pelos arquivos ainda no início da era Moderna. Outros estudos relacionam-se com a questão do poder de posse dos documentos em várias ocasiões, como no caso dos processos de descolonização da África e da Ásia (SILVA et al, 1998). Nas décadas de 1960 e 1970, debates sobre as políticas nacionais de informação promovidos pela Unesco tematizaram o papel dos arquivos, a questão do direito à informação e a necessidade de transparência por parte do Estado (JARDIM, 1995). Numa linha radicalmente diferente, autores como Colombo argumentaram contra a obsessão das sociedades contemporâneas com o arquivamento e o registro das atividades humanas. É na Arquivologia canadense, contudo, que se desenvolvem as principais perspectivas críticas contemporâneas. Com origem nos trabalhos de Terry Cook, tal corrente buscou superar os pressupostos de neutralidade e passividade das práticas arquivísticas, analisando em que medida os arquivos constituem espaços em que relações de poder são negociadas, contestadas e confirmadas - numa virada de ênfase das coleções para os contextos. Autores como Caswell, Harris e Montgomery têm se debruçado sobre o estudo de realidades arquivísticas específicas, por exemplo em regimes totalitários, a partir de conceitos de Arendt e Derrida, a partir do caminho iniciado por Cook.

$\mathrm{Na}$ Biblioteconomia, manifestações de um pensamento crítico surgiram principalmente em países de terceiro mundo, vinculadas aos processos de redemocratização após ditaduras militares. Num primeiro momento, tais manifestações foram de caráter prático (com a criação de novos serviços bibliotecários de extensão, como o carro-biblioteca), com o objetivo de aumentar o acesso ao conhecimento por parte de populações socialmente excluídas. Anos depois, foram formuladas teorias relacionadas a essas práticas no escopo das reflexões sobre "ação cultural" e "animação cultural", nas quais buscava-se distinguir os diferentes tipos de ideologias culturais e propor que o bibliotecário deveria identificá-las e 
atuar perante elas, não numa perspectiva de "domesticação" mas sim de "emancipação" (FLUSSER, 1983). As bibliotecas deveriam ser dinâmicas e ativas, mas contra os processos de alienação - num sentido bem diferente da perspectiva funcionalista (MILANESI, 2002). Estudos críticos muito diferentes também se desenvolveram em outros países, como na França, em que autores como Estivals, Meyriat e Breton se uniram em torno de uma abordagem marxista para estudar os diferentes circuitos do livro e do documento impresso (ESTIVALS, 1981).

$\mathrm{Na}$ Museologia, as manifestações pioneiras de pensamento crítico se encontram na obra de artistas e ensaístas como Zola, Valéry e Marinetti (BOLAÑOS, 2002), que viam o museu como "mausoléu", instituição que degradava a arte, instrumento de poder de alguns povos sobre outros. Na década de 1960, uma nova onda de críticas provocou o aparecimento de formas de "antimuseu" (BOLAÑOS, 2002), com importantes inovações museológicas. Porém, é na aproximação com a sociologia da cultura que estão as manifestações mais consolidadas da perspectiva crítica, com Bourdieu inspirando toda uma geração de pesquisadores. Bourdieu aliou as dimensões material e simbólica, analisando como diferentes grupos sociais têm relações distintas com a cultura (e inclusive com os museus). Abordagens atuais utilizam-se desse referencial e do conceito de "capital cultural" para o estudo de distintas práticas museológicas (LOPES, 2007). Outros estudos buscam correlacionar o papel que os museus tiveram (e ainda têm) na construção ideológica da idéia de nação, a partir do trabalho pioneiro de Anderson. Há ainda uma área recente, a "Museologia Crítica", voltada para a crítica das estratégias museológicas intervenientes nos patrimônios naturais e humanos (SANTACANA MESTRE; HERNÁNDEZ CARDONA, 2006).

\section{Os estudos a partir da perspectiva dos sujeitos}

Arquivos, bibliotecas e museus sempre tiveram usuários ou visitantes. Durante a vigência do paradigma custodial, contudo, conhecê-los nunca foi uma prioridade. Nos primeiros anos do século XX, as abordagens funcionalistas começaram a se preocupar com o público, tentando obter dados sobre índices de satisfação para a melhoria dos serviços. Aos poucos, a importância de se conhecer a visão dos sujeitos concretos que se relacionam com estas instituições foi aumentando, a ponto de acabar se tornando uma área de estudos autônoma. Os usuários e visitantes deixaram de ser vistos apenas como alvo dos processos arquivísticos, biblioteconômicos e museológicos, sendo compreendidos como seres ativos, 
construtores de significados e interpretações próprias, com necessidades e estratégias diversas. A compreensão dessas novas questões trouxe relevantes impactos para a teoria e para a prática.

No campo da Arquivologia, o tema da relação entre os usuários e os arquivos começou a ser discutido na década de 1960 (SILVA et al, 1998), dentro das reflexões sobre o acesso aos arquivos nas reuniões do Conselho Internacional de Arquivos (CIA). Contudo, a temática sempre foi muito pouco expressiva no campo. Conforme Jardim e Fonseca (2004), estudos pioneiros são os de Taylor, Dowle, Dearstyne, Pugh, Cox e Wilson, voltados para o entendimento das necessidades informacionais de diferentes tipos de usuários. Há também estudos de usuários no campo dos trabalhos de dinamização cultural, principalmente sobre tipologia de usuários e, mais recentemente, sobre cidadãos e seus interesses em história familiar e em atividades de ensino (COEURÉ; DUCLERT, 2001).

$\mathrm{Na}$ Biblioteconomia, as primeiras manifestações foram os "estudos de comunidade" realizados por pesquisadores da Universidade de Chicago, que tinham como foco os grupos sociais tomados em seu conjunto. Foram realizadas diversas pesquisas empíricas, nas três décadas seguintes, sobre hábitos de leitura e fontes de informação mais usadas. Aos poucos, o interesse foi se deslocando para a avaliação dos serviços bibliotecários, convertendo os estudos de usuários em estudos de uso para diagnóstico de bibliotecas. Situando-se na temática de Avaliação de Coleções, tais estudos impulsionaram várias inovações técnicas, tais como a disseminação seletiva de informações. Na década de 1970, pesquisadores como Line, Paisley, Brittain e Totterdall deslocaram o foco de interesse para as necessidades de informação, que se converteram, na década seguinte, na principal linha de pesquisa sobre os usuários (FIGUEIREDO, 1994). Recentemente, destacam-se as pesquisas de autores como Kuhlthau e Todd no ambiente da biblioteca escolar, numa perspectiva cognitivista, identificando o uso da informação nas diferentes fases do processo de pesquisa escolar.

$\mathrm{Na}$ Museologia, como parte da grande mudança nos museus, de depósitos de objetos para lugares de aprendizagem, operou-se uma alteração do foco, das coleções para os públicos - surgindo desse movimento a subárea de Estudos de Visitantes (HOOPER-GREENHILL, 1998). No começo do século $X X$ foram realizados os primeiros estudos empíricos, com Galton seguindo os visitantes pelos corredores dos museus e Gilman estudando a fadiga e os problemas de ordem física na concepção de exposições. As primeiras investigações com maior rigor ocorreram no final da década de 1920, com patrocínio da Associação Americana 
de Museus - sendo o primeiro estudo de comportamento dos visitantes publicado por Robinson em 1928. Na década de 1940, proliferaram estudos sobre os impactos nas exposições junto aos visitantes, realizados por autores como Cummings, Derryberry e Melton. Outros estudos, conduzidos por autores como Rea e Powell na mesma época, tiveram como objetivo traçar perfis sócio-demográficos dos visitantes e mapear seus hábitos culturais (PÉREZ SANTOS, 2000). Na década de 1960, Shettel e Screven inauguraram uma nova perspectiva com as medidas de aprendizagem nos estudos de visitantes. Nas décadas seguintes, desenvolveram-se abordagens de base cognitivista, sobre a efetividade das exposições (Eason, Friedman, Borun), e de natureza construtivista - como o modelo tridimensional de Loomis, a teoria dos filtros de McManus, o modelo sociocognitivo de Uzzell, a abordagem comunicacional de Hooper-Greenhill e o modelo contextual de Falk e Dierking. Em comum, essas várias abordagens buscaram ver como os usuários interpretam as exposições museográficas, construindo significados diversos, imprevisíveis, relacionados com suas distintas vivências, experiências e contextos socioculturais, (DAVALLON, 2005).

\section{Estudos sobre representação}

Desde sua origem, os arquivos, as bibliotecas e os museus se depararam com o desafio de representar suas coleções - inventariá-las para fins de controle e guarda, catalogá-las e classificá-las para fins de recuperação, descrevê-las para facilitar o acesso e o uso. Tal desafio foi historicamente concebido como uma questão técnica - encontrar as formas mais adequadas para atingir os objetivos. Nos séculos XVIII e XIX, o enciclopedismo, o historicismo e o positivismo marcaram fortemente as tarefas de representação com a proposição de esquemas universais de representação. Ao longo do século XX, contudo, diferentes teorias buscaram problematizar esses processos, conformando aos poucos uma subárea de estudos com forte influência das ciências da linguagem. De tarefa técnica, as questões da representação se converteram em importante campo de investigação científica.

A temática relativa a princípios de organização e descrição de documentos arquivísticos surgiu e foi debatida durante todo o período de consolidação do paradigma custodial. A partir de 1898, com a publicação do manual dos holandeses Muller, Feith e Fruin, ela ganhou um estatuto diferente, abrindo-se caminho para a construção de um espaço reflexivo sobre as normas e técnicas arquivísticas. Diversas aplicações práticas de instrumentos de classificação, inclusive de sistemas de classificação bibliográfica, foram 
testados nos anos seguintes, embora sem uma significativa reflexão teórica - o que só aconteceu em manuais posteriores, como os de Tascón, de 1960, e de Tanodi, em 1961, e em obras teóricas de pesquisadores como Schellenberg. Nas décadas de 1970 autores como Laroche e Duchein problematizaram os princípios de ordenamento confrontando o conceito de record group surgido nos EUA com o princípio da proveniência europeu. No final desta década, autores como Dollar e Lytle inseriram a questão dos registros eletrônicos e a recuperação da informação (SILVA et al, 1998). Os aspectos relacionados com preservação e autenticidade também estiveram no centro dos debates sobre os documentos digitais, envolvendo pesquisadores como Duranti e Lodolini, que buscaram confirmar o valor do princípio de proveniência e o respeito aos fundos como critério fundamental da Arquivologia. O impacto dos suportes digitais também motivou o crescimento da pesquisa na área de normalização arquivística (SILVA, 2008), principalmente a partir da ideia de interoperabilidade de sistemas e possibilidade de ligação em rede, envolvendo pesquisadores, associações profissionais e entidades governamentais. A temática da indexação dos documentos arquivísticos (representação por assuntos) também vem ganhando espaço nos últimos anos (RIBEIRO, 2003).

As questões relacionadas com a descrição e a organização estão na origem mesma da fundação da Biblioteconomia como campo autônomo de conhecimento. A Catalogação, relacionada com a descrição dos aspectos formais dos documentos, teve suas primeiras regras e princípios formulados ainda no século XIX. A partir da década de 1960, padrões internacionais de descrição bibliográfica foram formulados e envolveram diversos grupos de estudo. Também nesta época surgiram os primeiros modelos de descrição pensando-se na leitura por computador, gerando padrões que, anos depois, conformariam o campo conhecido como Metadados. Paralelamente, a área de Classificação teve início com a criação dos primeiros sistemas de classificação bibliográfica gerais e enumerativos, como os de Dewey, Otlet, Bliss e Brown. Na primeira metade do século XX, os trabalhos de Ranganathan sobre classificação facetada revolucionaram o campo, propondo formas flexíveis e nãohierarquizadas de classificação. Suas teorias tiveram grande impacto na ação do Classification Research Group, fundado em Londres em 1948, que congregou pesquisadores como Foskett, Vickery e Pendleton, empenhados na construção de sistemas facetados para domínios específicos de conhecimento e problematização dos princípios de classificação (SOUZA, 2007). Nos anos seguintes, diversos campos e setores de pesquisa estabeleceram diálogo ou se apropriaram dos princípios da classificação facetada, tais como os tesauros facetados de 
Aitchison, a Teoria do conceito de Dahlberg, os estudos de bases de dados facetados de Neelameghan, a abordagem dos boundary objects de Albrechtsen e Jacob, as pesquisas em estruturas de classificação de Kwasnik, e o mapeamento de sentenças para a evidenciação de facetas por Beghtol. Por fim, merecem ainda destaque os estudos em linguagens de indexação, cujos pioneiros são Austin e Farradane.

O espírito nacionalista e historiográfico dos primeiros museus modernos foi decisivo para a configuração de critérios de ordenamento, descrição, classificação e exposição dos acervos (MENDES, 2009). A subárea de Documentação Museológica surgiu no início do século XX, a partir do trabalho de autores como Wittlin, Taylor e Schnapper (MARÍN TORRES, 2002). Nas décadas de 1920 e 1930 houve grandes debates sobre os critérios de classificação adotados nos museus, mas a temática só se converteu em campo de investigação décadas depois. Entre as várias abordagens desenvolvidas, encontram-se aquelas que buscaram problematizar aspectos classificatórios dos museus, como a questão da representação dos gêneros, dos diferentes povos do mundo, das diferentes culturas humanas, numa linha marcada pelos cultural studies (PEARCE, 1994). Os aspectos envolvidos no trabalho de ordenamento também foram estudados por Bennett numa perspectiva foucaultiana. No campo das aplicações práticas, Bolaños (2002) apresenta vários exemplos históricos de inovações em métodos de representação, como o historicismo radical de Dorner, os period rooms do Museu do Prado, o enfoque multidisciplinar do Museu de Arte Moderna de Nova Iorque, a postura antiracista do Museu Trocadero e o modelo dinâmico do Museu de Etnografia de Neuchâtel, merecendo destaque, recentemente, a criação de edifícios que em si mesmos constituem peças museológicas, numa perspectiva inaugurada com o Museu Guggenheim de Bilbao.

\section{Abordagens contemporâneas: fluxos, mediações, sistemas}

Os avanços mais recentes nos campos da Arquivologia, Biblioteconomia e Museologia têm buscado agregar as várias contribuições das últimas décadas. Novos tipos de instituições, serviços e ações executadas no âmbito extra-institucional conferiram maior dinamismo aos campos, que passaram a se preocupar mais com os fluxos e a circulação de informação. Buscando superar os modelos voltados apenas para a ação das instituições junto ao público, ou para os usos e apropriações que o público faz dos acervos, surgiram modelos voltados para a interação e a mediação, contemplando as ações reciprocamente referenciadas destes atores.

InCID: R. Ci. Inf. e Doc., Ribeirão Preto, v. 2, n. 2, p. 19-41, jul./dez. 2011. 
Modelos sistêmicos também apareceram na tentativa de integrar ações, acervos ou serviços antes contemplados isoladamente. A própria ideia de acervo, ou coleção, foi problematizada, na esteira de questionamentos sobre o objeto da Arquivologia, da Biblioteconomia e da Museologia. Somado a tudo isso, desenvolveram-se as tecnologias digitais com um impacto muito mais profundo, reconfigurando tanto o fazer quanto a teorização destes três campos.

Na Arquivologia, na década de 1960, houve uma maior teorização sobre o objeto do campo (destacando-se o pioneirismo de Tanodi que, em 1961 definiu o objeto como sendo a "arquivalia"); uma ampliação de seus domínios (como os arquivos administrativos, os arquivos privados e de empresas); e ainda o surgimento de campos novos (os arquivos sonoros, visuais e o uso do microfilme). Tais avanços tiveram como consequência a criação, na década seguinte, do Programa de Gestão dos Documentos e dos Arquivos (RAMP), estrutrurado pelo CIA e pela Unesco, no âmbito de seu Programa Geral de Informação (PGI) criado em 1976. Tal programa assegurou a publicação de importantes trabalhos em diferentes áreas da Arquivologia, tais como os de Kula (avaliação de arquivos de imagens em movimento); de Naugler (registros eletrônicos); de Guptil (documentos de organizações internacionais); de Harrison e Schuurma (arquivos sonoros) e de Cook (documentos contendo informações pessoais). Contudo, a maior inovação teórica, a Arquivística Integrada, surgiu no começo dos anos 1980 com o artigo inaugural de Ducharme e Rousseau, que apresenta uma visão sistêmica do fluxo documental. Dois anos depois, Couture e Rousseau formalizaram a busca de uma síntese dos records management e da archives administration, a partir de uma visão global dos arquivos, considerando a gestão de documentos no campo de ação da Arquivologia, isto é, abarcando as tradicionalmente chamadas três idades dos documentos numa perspectiva integrada. Tal abordagem passou a desenvolver-se de formas específicas por autores de variados contextos, tais como Cortés Alonso e Conde Villaverde na Espanha, Menne-Haritz na Alemanha, Cook na Inglaterra e Vásquez na Argentina. Pouco depois, surgiu a expressão "pós-custodial" para designar uma nova fase da Arquivologia (COOK, 1997). Nessa mesma linha desenvolveu-se a perspectiva sistêmica em torno da ideia de "arquivo total" em Portugal, congregando pesquisadores como Silva e Ribeiro (SILVA et al, 1998). Outras temáticas contemporâneas são as que relacionam os arquivos com as atividades de registro da história oral, e o campo dos arquivos pessoais e familiares (COX, 2008).

Dentro das abordagens contemporâneas em Biblioteconomia, destacam-se três grandes tendências que, embora possam ser separadamente identificadas, possuem vários elementos em comum. A primeira delas é a que se apresenta contemporaneamente sob a designação de 
"Mediação". Tal vertente foi primeiramente trabalhada por Ortega y Gasset, em 1935, num sentido de ponte, filtro, sendo o bibliotecário um orientador de leituras dos usuários. Anso depois, expressou-se numa alteração estrutural do conceito de biblioteca, sendo esta considerada "menos como 'coleção de livros e outros documentos, devidamente classificados e catalogados' do que como assembléia de usuários da informação” (FONSECA, 1992, p. 60). Assim, a ideia de mediação sofreu uma mudança, enfatizando menos o caráter difusor (de transmissão de conhecimentos) e mais o caráter dialógico da biblioteca (ALMEIDA JR., 2009). A segunda vertente também pode ser entendida como parte dos estudos sobre mediação, embora tenha se desenvolvido de modo mais específico. Trata-se do campo desenvolvido a partir do conceito de "Information Literacy", surgido nos EUA em 1974, voltado para a identificação e a promoção de habilidades informacionais dos sujeitos, que não são mais entendidos apenas como usuários portadores de necessidades informacionais (Campello, 2003). Por fim, a terceira vertente é a dos estudos sobre as bibliotecas eletrônicas ou digitais, com todas as implicações em termos de acervos, serviços e dinâmicas relativas a essa nova condição (ROWLEY, 2002).

Na Museologia, merece destaque o desenvolvimento dos ecomuseus e da chamada Nova Museologia. Conforme Davis (1999), o conceito de "ecomuseu" surgiu no começo do século XX, sob o impacto das ideias ambientalistas, de conceitos relativos à ecologia e ecossistemas, com a criação dos "museus ao ar livre", que, numa perspectiva ampliada de museu, incorporavam sítios geológicos ou naturais ao seu "acervo". Um outro sentido para o termo foi dado, a partir das ideias de Rivière, Hugues de Varine e Bazin, pela Nova Museologia, que propôs repensar o significado da própria instituição museu. Nessa visão, os museus deveriam envolver as comunidades locais no processo de tratar e cuidar de seu patrimônio. Tal proposta foi apresentada pela primeira vez em 1972, numa Mesa Redonda de Santiago do Chile, organizada pelo International Council of Museums (ICOM), sendo formalizada na Declaração de Quebec, em 1984. Do ponto de vista teórico, tal noção propõe que a Museologia passe a estudar a relação das pessoas com o patrimônio cultural e que o museu seja entendido como instrumento e agente de transformação social - o que significa ir além das suas funções tradicionais de identificação, conservação e educação, em direção à inserção da sua ação nos meios humano e físico, integrando as populações. Defendendo a participação comunitária no lugar do "monólogo" do técnico especialista, tais ideias colocaram no lugar do tradicional tripé edifício/coleções/público da Museologia uma nova rede de conceitos, composta por território, patrimônio e comunidade. Deve-se distinguir, 
porém, essa Nova Museologia dos recentes estudos com a mesma designação, propostos por Vergo e Marstine, entre outros, que representam, antes, uma revitalização do pensamento funcionalista. Soma-se a isso a recente ênfase nos estudos sobre a musealização do patrimônio imaterial. Por fim, o fenômeno contemporâneo dos museus virtuais representa uma dimensão com variados desdobramentos práticos e teóricos. Para Deloche (2002), a chegada da tecnologia digital à realidade dos museus acarreta a reformulação da própria concepção de instituição museal. Sem edifício ou coleções, marcos institucionais tradicionais definidores do próprio campo, o museu se vê na condição de oferecer novos serviços, por meio de novas práticas e funções, a usuários que também ganham novas condições de ação. Ao mesmo tempo, a adoção de tecnologias tanto para o tratamento como para o planejamento de exposições aproxima o museu do conceito de sistema de informação. Nesse sentido, têm sido desenvolvidos estudos numa área específica denominada "Museum Informatics", que trata das interações sociotécnicas (entre as pessoas, a informação e a tecnologia) nos espaços museais (MARTY; JONES, 2008).

\section{A Ciência da Informação}

As raízes da CI se encontram na área de Documentação, criada por Otlet e La Fontaine no início do século XX. Preocupados com a disponibilização de registros sobre a totalidade do conhecimento humano (mais do que com o armazenamento destes registros), os autores desenvolveram o conceito de "documento", alargando o campo de intervenção para além dos livros e demais registros impressos. Embora tratando de arquivos, bibliotecas e museus numa perspectiva integradora, a área acabou se desenvolvendo como uma atividade profissional distinta, paralela, atuando principalmente no campo da informação científica e tecnológica.

Foi justamente neste espectro de atuação, do registro e fornecimento de informações para campos específicos de ciência e tecnologia, que começaram a atuar aqueles que primeiramente ficaram conhecidos como "cientistas da informação" (FEATHER; STURGES, 2003). Na esteira das tentativas de institucionalização das atividades destes profissionais deuse a base para a criação da nascente "Ciência da Informação". Para Shera e Cleveland (1977), o acontecimento que teria marcado a transformação da Documentação em CI foi a International Conference on Scientific Information, realizada em Washington, em 1958. Poucos anos depois, em 1966, o American Documentation Institute (ADI) mudou sua designação para American Society for Information Science (ASIS), tornando-se a primeira

InCID: R. Ci. Inf. e Doc., Ribeirão Preto, v. 2, n. 2, p. 19-41, jul./dez. 2011. 
instituição científica específica da CI. Os fundamentos teóricos imediatamente adotados foram a Teoria Matemática da Comunicação de Shannon e Weaver, a Cibernética de Wierner e as contribuições de Vannevar Bush. Juntos, permitiram a elaboração de um conceito "científico" de informação e a agenda de pesquisa da área, expressa num artigo de Borko, publicado em $1968^{1}$, que se tornou um clássico.

Contudo, o que viria a ser a CI nos anos seguintes ultrapassou em muito o imaginado nos primeiros anos. Conforme González de Gómez (2000), nas décadas seguintes a CI desenvolveu-se por meio de subáreas relacionadas a diversos "programas de pesquisa": os fluxos da informação científica, a recuperação da informação, os estudos métricos da informação, os estudos de usuários, as políticas de informação, a gestão do conhecimento e as possibilidades trazidas com o hipertexto e a interconectividade digital. O objeto de estudo do campo ampliou-se para além dos registros físicos em sistemas de informação. Foram estudados, por exemplo, os "colégios invisíveis" (processos de troca de informação em ambiente informal), o "conhecimento tácito", as necessidades de informação e as competências informacionais dos sujeitos, entre outros.

Segundo Capurro (2003), as diferentes teorias e subáreas acabaram por consolidar três amplos modelos de estudo do fenômeno informacional: o físico (que privilegia a idéia de informação como "coisa" a ser transferida de um ponto a outro), o cognitivo (inspirado na filosofia de Popper e que enfatiza a informação como elemento alterador dos modelos mentais dos usuários) e o social (que busca entender o que é informação por parte de comunidades de usuários, resgatando a idéia de construção intersubjetiva).

Silva (2006) também expressou essa ampliação por meio da definição das seis "propriedades" da informação como conceito científico. A informação é algo comunicável, reprodutível e quantificável (pode-se dizer que correspondem ao conceito "físico" de Capurro); possui pregnância de sentido (corresponde à dimensão "cognitiva" identificada por Capurro); integra-se de forma dinâmica a seu contexto e é estruturada pela ação humana (corresponde à dimensão "social” de Capurro).

A CI tem sido caracterizada, ainda, como uma ciência interdisciplinar (SARACEVIC, 1996), pós-moderna (WERSIG, 1993) e pertencente ao campo das ciências humanas e sociais (GONZÁLEZ DE GÓMEZ, 2000). Tais características a têm credenciado como um campo flexível, capaz de fazer dialogar e interagir, dentro dela, campos disciplinares distintos; crítico

\footnotetext{
${ }^{1}$ BORKO, H. Information science: what is it? American Documentation, Jan. 1968.
}

InCID: R. Ci. Inf. e Doc., Ribeirão Preto, v. 2, n. 2, p. 19-41, jul./dez. 2011. 
aos limites do Positivismo e ao mesmo tempo sensível às especificidades da atual "sociedade da informação"; e capaz de permitir a convivência de diferentes escolas e correntes teóricas.

\section{A possibilidade de integração epistemológica}

Os avanços teóricos na Arquivologia, Biblioteconomia e Museologia apontam para a efetiva superação do modelo custodial consolidado no final do século XIX - segundo o qual estas ciências seriam dedicadas ao estudo dos "tesouros" guardados e patrimonializados, das rotinas institucionais das entidades dedicadas à sua guarda e dos procedimentos de tratamento técnico dos acervos. Ao propor o estudo das relações entre essas instituições e a sociedade (tanto na perspectiva funcionalista como na crítica), ao focar o ponto de vista dos sujeitos, ao problematizar os aspectos relacionados ao significado nas representações e ao pensar os fluxos e as mediações, as teorias desenvolvidas no século XX tensionaram os limites das áreas de conhecimento. Assim, a dinâmica mais ampla dos processos passou a ser contemplada, com objetos que vão desde a produção dos registros (e até mesmo o que ainda não possui existência física, o imaterial), a composição dos acervos, as competências dos usuários no uso e apropriação dos acervos, até as diferentes camadas de significação criadas com a intervenção profissional e os instrumentos de descrição e classificação. Na Museologia, tal passagem pode ser caracterizada com a mudança do objeto "museu" para a "musealidade" ou a "musealização" (STRÁNSKÝ apud DELOCHE, 2002); na Arquivologia com o conceito de "arquivalia" ou o de "arquivo total" (SILVA et al, 1998); e na Biblioteconomia com o próprio conceito de "informação" (como vem sendo feito desde a década de 1980, quando as pósgraduações em Biblioteconomia começaram a mudar sua denominação para CI).

A CI aparece, então, como campo profícuo para os avanços reivindicados pela evolução das várias teorias desenvolvidas e para fazer dialogarem e interagirem dentro dela as três áreas. Além disso, constituindo-se desde o início como ciência, é capaz de proporcionar o efetivo espaço de reflexão e problematização, buscando superar o caráter eminentemente prático, de aplicação de regras, que as disciplinas de arquivo, biblioteca e museu trazem de sua origem.

O conceito de informação também é relevante, mas, para que ele propicie essa integração, é preciso retornar à própria origem do termo, que, conforme Capurro (2008), remonta aos conceitos gregos de eidos (ideia) e morphé (forma), significando "dar forma a 
algo". Informação, portanto, se inscreve no âmbito da ação humana sobre o mundo ("informar"), apreendendo-o por meio do simbólico, nomeando e classificando os objetos que conhece (objetos da natureza), criando objetos que passa a utilizar (instrumentos com as mais diversas finalidades), produzindo registros que constituem novos objetos (textos impressos, visuais, sonoros) e criando ainda registros destes registros (catálogos, índices, inventários, etc).

Informação é portanto um conceito que perpassa todo esse processo. Tem origem na produção de registros materiais e se prolonga nas atividades humanas (arquivísticas, biblioteconômicas, museológicas) sobre esses registros. Mas é ainda mais ampla do que isso, é tudo aquilo que envolve essa ação humana a partir do primeiro registro, do primeiro ato de “in-formar". Parte da ação humana comum, cotidiana, de apreender o mundo e produzir registros materiais desse processo, chega às instituições e procedimentos técnicos criados especificamente para intervir junto a estes registros e os ultrapassa nos mais diversos usos, fluxos, apropriações, contextos. Dada sua amplitude, surge com grande potencial de tratar os variados processos arquivísticos, biblioteconômicos e museológicos como sendo muito mais do que os procedimentos técnicos definidos pelo paradigma custodial/tecnicista. Ao fazer isso, potencializa também uma parcial dissolução das rígidas fronteiras disciplinares (sem perda de identidade e de especificidade de cada uma) em benefício de reflexões teóricas e aplicações práticas mais ricas - como demonstram, entre outros, os recentes exemplos de construção da Europeana (um amplo sistema digital que constitui ao mesmo tempo um arquivo, uma biblioteca e um museu de acervos da cultura europeia) ou a fusão do Arquivo Nacional e da Biblioteca Nacional no Canadá. Enfim, a CI, sem se impor sobre as três áreas, e ficando aberta às especificidades e contribuições de cada uma, proporciona o diálogo necessário para a construção de um conhecimento científico que não se reduz ao estudo e à prática das instituições que cada área contempla. A CI possibilita que as três áreas sejam mais do que "a ciência do arquivo", "a ciência da biblioteca" e "a ciência do museu" - e ainda se enriqueçam mutuamente. 


\section{Referências}

ALBERCH I FUGUERAS, R. et al. Archivos y cultura: manual de dinamización. Gijón: TREA, 2001.

ALMEIDA JR., O. Mediação da informação e múltiplas linguagens. Tendências da Pesquisa Brasileira em Ciência da Informação, Brasília, v. 2, n. 1, p. 89-103, jan./dez. 2009.

BOLAÑOS, M. La memoria del mundo: cien años de museología: 1900-2000. Gijón: TREA, 2002.

CAMPELLO, B. O movimento da competência informacional: uma perspectiva para o letramento informacional. Ciência da Informação, Brasília, v. 32, n. 3, p. 28-37, set./dez. 2003.

CAPURRO, R. Pasado, presente y futuro de la noción de información. In: ENCUENTRO INTERNACIONAL DE EXPERTOS EM TEORÍAS DE LA INFORMACIÓN, 1, 2009. Anais... Leon: Universidad de Leon, 2008.

CAPURRO, R. Epistemologia e ciência da informação. In: ENCONTRO NACIONAL DE PESQUISA EM CIÊNCIA DA INFORMAÇÃO, 5., 2003, Belo Horizonte. Anais... Belo Horizonte: Associação Nacional de Pesquisa e Pós-Graduação em Ciência da Informação, 2003.

COEURÉ, S.; DUCLERT, V. Les archives. Paris: La Découverte, 2001.

COOK, T. What is past is prologue: a history of archival ideas since 1898, and the future paradigm shift. Archivaria, v. 43, p. 17-63, 1997.

COX, R. Personal archives and a new archival calling: readings, reflections and ruminations. Duluth: Litwin, 2008.

DAVALLON, J. Penser la muséologie. In: DAVALLON, J.; SCHIELE, B. Doctorat en Museólogie, mediation, patrimoine. Sainte-Foy: Multimondes, 2005, p. 69-98.

DAVIS, P. Ecomuseums: a sense of place. London:Leicester University Press, 1999.

DELOCHE, B. El museo virtual. Gijón: TREA, 2002.

DELSALLE, P. Une histoire de l'archivistique. Sainte-Foy: Presses de l'Université du Québec, 2000.

ESTIVALS, R. A dialética contraditória e complementar do escrito e do documento. Revista da Escola de Biblioteconomia da UFMG, Belo Horizonte, v. 10, n. 2, p. 121-152, set. 1981.

FEATHER, J.; STURGES, P. International Encyclopedia of Information and Library Science. Londres: Routledge, 2003.

FIGUEIREDO, N. Estudos de uso e usuários da informação. Brasília: IBICT, 1994. 
FLUSSER, V. A biblioteca como um instrumento de ação cultural. Revista da Escola de Biblioteconomia da UFMG, Belo Horizonte, v. 12, n.2, p. 145-169, set. 1983.

FONSECA, E. Introdução à biblioteconomia. São Paulo: Pioneira, 1992.

GÓMEZ MARTÍNEZ, J. Dos museologías: las tradiciones anglosajona y mediterránea diferencias y contactos. Gijón: Trea, 2006.

GONZÁLEZ DE GÓMEZ, M. Metodologia de pesquisa no campo da Ciência da Informação. DataGramaZero - Revista de Ciência da Informação, v.1, n.6, dez. 2000.

HOOPER-GREEENHILL, Eilean. Los museos y sus visitantes. Gijón: Trea, 1998.

JARDIM, J.M., FONSECA, M.O. Estudos de usuários em arquivos: em busca de um estado da arte. Datagramazero, v. 5, n. 5, out. 2004.

JARDIM, J. M. Sistemas e políticas públicas de arquivos no Brasil. Niterói: EdUff, 1995.

LOPES, J. Da democratização à democracia cultural. Porto: Profedições, 2007.

LÓPEZ CÓZAR, E. La investigación en biblioteconomía y documentación. Gijón: Trea, 2002.

MARÍN TORRES, M. T. Historia de la documentación museológica: la gestión de la memoria artística. Gijón: TREA, 2002.

MARTY, P.; JONES, K. (orgs). Museum informatics: people, information and technology in museums. Nova Iorque: Routledge, 2008.

MENDES, J. Estudos do patrimônio: museus e educação. Coimbra: Univ. Coimbra, 2009.

MILANESI, L. Biblioteca. São Paulo: Ateliê, 2002.

MURISON, W. The public library: its origins, purpose and significance. Londres: C. Bingley, 1988.

PEARCE, S. (ed). Museums and the appropriation of culture. Londres: Athlone, 1994.

PÉREZ SANTOS, E. Estudio de visitantes en museos: metodología y aplicaciones. Gijón: Trea, 2000.

RIBEIRO, F. O acesso à informação nos arquivos. Lisboa: Fundação Calouste Gulbenkian; MCT; MCEC, 2003.

ROWLEY, J. A biblioteca eletrônica. Brasília: Briquet de Lemos, 2002.

SANTACANA MESTRE, J.; HERNÁNDEZ CARDONA, F. Museologia crítica. Gijón: Trea, 2006.

SARACEVIC, T. Ciência da informação: origem, evolução e relações. Perspectivas em Ciência da Informação. Belo Horizonte, v.1, n.1, p. 41-62, jan./jun. 1996. 
SHERA, J.; CLEVELAND, D. History and foundations of information science. Journal of the American Society of Information Science and Technology, v. 12, p. 249-275, 1977.

SILVA, A. M. et al. Arquivística: teoria e prática de uma ciência da informação. Porto: Afrontamento, 1998.

SILVA, A. M. A informação: da compreensão do fenômeno e construção do objecto científico. Porto: Afrontamento, 2006.

SILVA, E. A trajetória da arquivologia: três visões sobre os arquivos. In: Congresso Nacional de Arquivologia, 3, 2008. Anais... Rio de Janeiro: Executiva Nacional das Associações Regionais de Arquivologia, 2008.

SOUZA, R. Organização do conhecimento. In: TOUTAIN, Lídia (Org). Para entender a ciência da informação. Salvador: EdUFBA, 2007, p. 103-123.

WERSIG, G. Information science: the study of postmodern knowledge usage. Information processing \& management. v. 29, n. 02, p. 229-239, mar. 1993.

ZELLER, T. The historical and philosophical foundations of art museum education in América. In: BERRY, N.; MAYER, S. (orgs). Museum education: history, theory and practice. Reston: National Art Education Association, 1989, p. 10-89. 